San Jose State University

SJSU ScholarWorks

Master's Theses

Master's Theses and Graduate Research

1989

\title{
Back-injury and the stressors of frustration and overload among nursing personnel in an acute hospital
}

Karen Gabrielson

San Jose State University

Follow this and additional works at: https://scholarworks.sjsu.edu/etd_theses

\section{Recommended Citation}

Gabrielson, Karen, "Back-injury and the stressors of frustration and overload among nursing personnel in an acute hospital" (1989). Master's Theses. 3136.

DOI: https://doi.org/10.31979/etd.ybe4-e56b

https://scholarworks.sjsu.edu/etd_theses/3136

This Thesis is brought to you for free and open access by the Master's Theses and Graduate Research at SJSU ScholarWorks. It has been accepted for inclusion in Master's Theses by an authorized administrator of SJSU ScholarWorks. For more information, please contact scholarworks@sjsu.edu. 


\section{INFORMATION TO USERS}

The most advanced technology has been used to photograph and reproduce this manuscript from the microfilm master. UMI films the text directly from the original or copy submitted. Thus, some thesis and dissertation copies are in typewriter face, while others may be from any type of computer printer.

The quality of this reproduction is dependent upon the quality of the copy submitted. Broken or indistinct print, colored or poor quality illustrations and photographs, print bleedthrough, substandard margins, and improper alignment can adversely affect reproduction.

In the unlikely event that the author did not send UMI a complete manuscript and there are missing pages, these will be noted. Also, if unauthorized copyright material had to be removed, a note will indicate the deletion.

Oversize materials (e.g., maps, drawings, charts) are reproduced by sectioning the original, beginning at the upper left-hand corner and continuing from left to right in equal sections with small overlaps. Each original is also photographed in one exposure and is included in reduced form at the back of the book. These are also available as one exposure on a standard 35mm slide or as a 17" $\times 23^{\prime \prime}$ black and white photographic print for an additional charge.

Photographs included in the original manuscript have been reproduced xerographically in this copy. Higher quality $6^{\prime \prime} \times 9^{\prime \prime}$ black and white photographic prints are available for any photographs or illustrations appearing in this copy for an additional charge. Contact UMI directly to order.

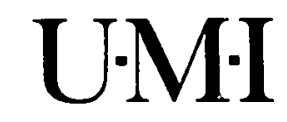

University Microfilms International 
Order Number 1988689

Back injury and the stressors of frustration and overload among nursing personnel in an acute hospital

\author{
Gabrielson, Karen, M.S.
}

San Jose State University, 1989

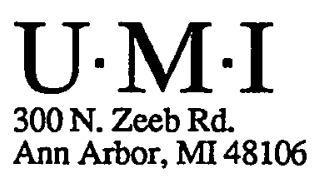




\title{
BACK-INJURY AND THE STRESSORS \\ OF FRUSTRATION AND OVERLOAD
}

AMONG NURSING PERSONNEL IN AN ACUTE HOSPITAL

\author{
A Thesis \\ Presented to \\ The Faculty of the Department of Nursing \\ San Jose State University
}

In Partial Fulfillment

of the Requirements for the Degree

Master of Science

By

Karen Gabrielson

August, 1989 
APPROVED FOR THE DEPARTMENT OF NURSING
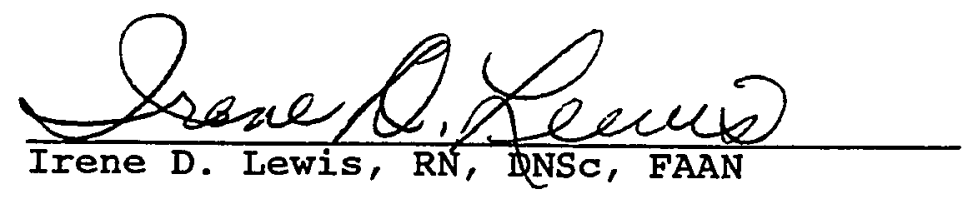

Sherman Ware

Sharon C. Wall, RN, MSN

Q: Sligflet

Bethany Shifflett, PhD

APPROVED FOR THE UNIVERSITY

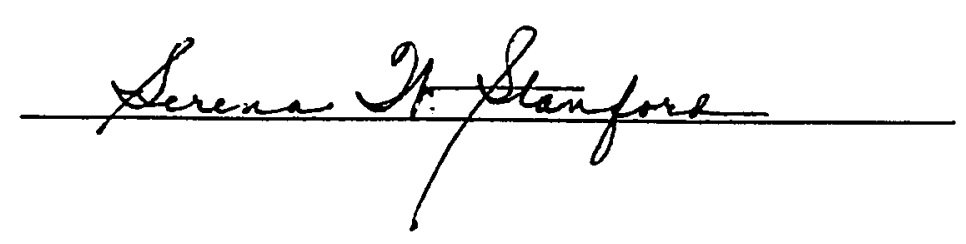




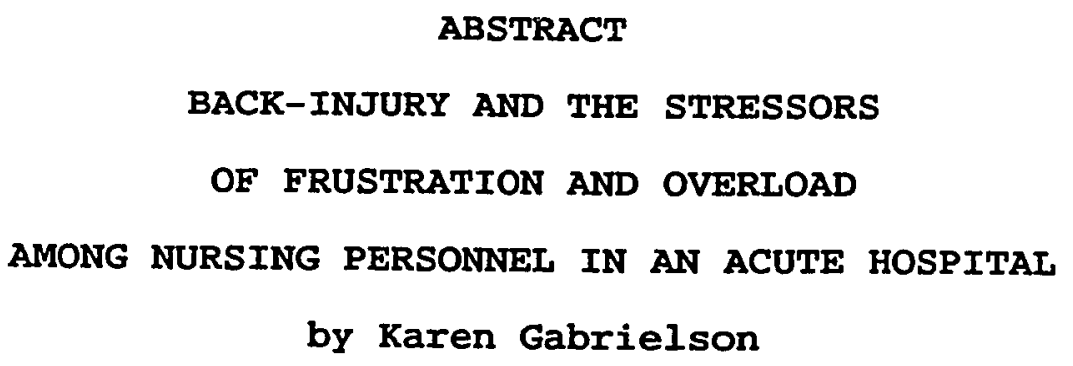

This study examined the difference between a back-injured and non-back-injured group of nursing personnel with respect to frustration and overload. Three survey instruments, two on frustration and overload (Girdano \& Everly, 1979) and a demographic questionnaire, were mailed. Findings: (a) There was no significant difference between group responses to frustration and overload. (b) The chi-square between group and exercise was significant. (c) The chi-square between group and deviation from normal weight for height and age was significant. Further research is needed to define back care, the optimal lifting method, and the role that stress, exercise, and normal weight play in back injury prevention. Clinical implications indicate a need for a complete back-injury prevention program in which awareness of back care, body mechanics, and risk factors all play a part. 
ACKNOWLEGDGEMENTS

The author wishes to thank

Dr. Bethany Shifflett

for her enthusiasm, encouragement

and statistical insight.

Thanks also to my husband

Roger and stepson

Jacob for proofreading.

Dedicated to the memory

of my grandmother

Fay Park-Hamilton. 


\section{TABLE OF CONTENTS}

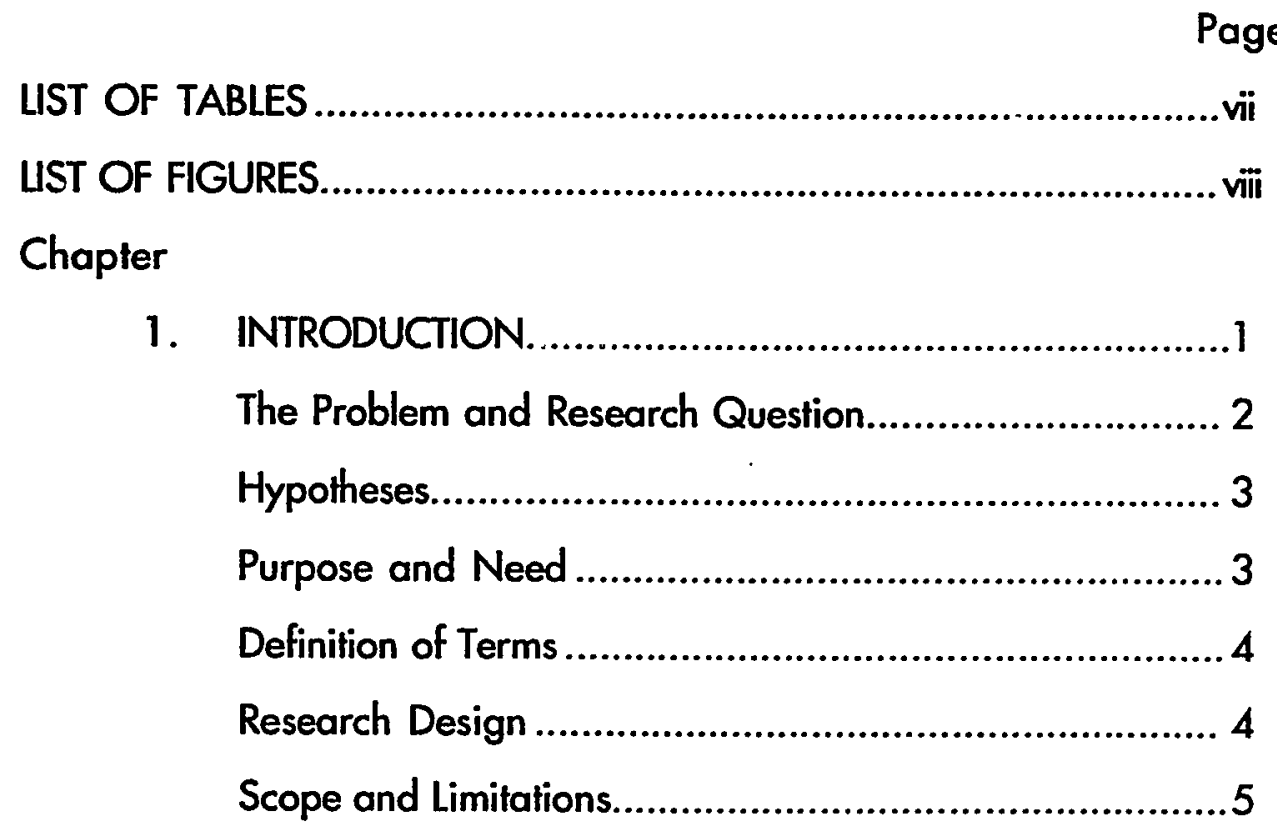

2. CONCEPTUAL FRAMEWORK

AND RELATED LITERATURE.........................................

Conceptual Framework ................................................. 7

Related Literature...................................................... 10

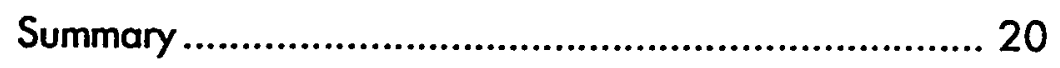

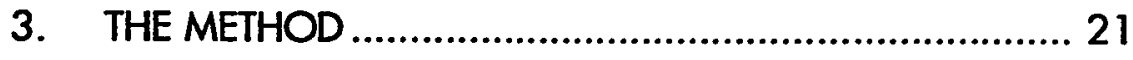

Research Design ........................................................ 21

The Setting and the Sample....................................... 21

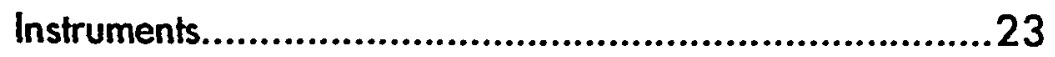

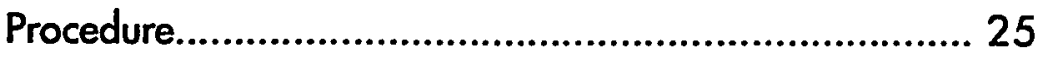

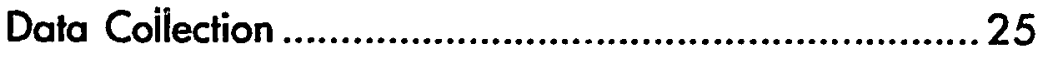

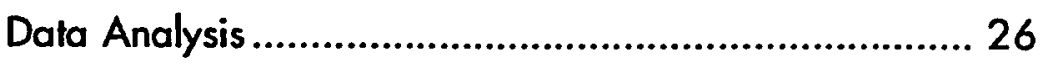


Chapter

4. ANALYSIS AND INTERPRETATION OF DATA............. 27

Description of the Sample ............................................ 27

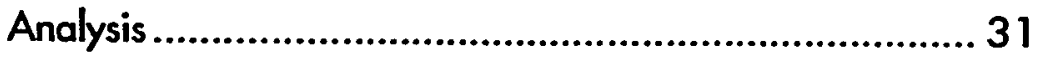

5. CONCLUSIONS AND RECOMMENDATIONS..............37

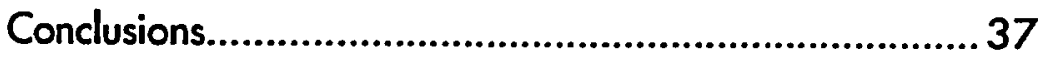

Recommendations .......................................................40

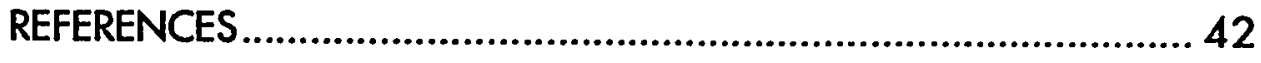

APPENDICES

A. Research Instruments............................................... 48

B. Consent Letter and Cover Letter ................................ 54

C. Permission Lefter........................................................ 57

D. Human Subjects Approval ..........................................59 


\section{List of Tables}

Table

Page

1. Frequency Distribution

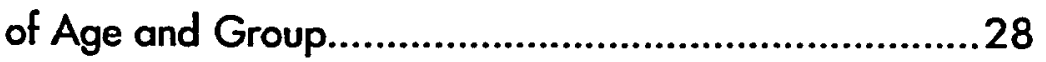

2. Frequency of Years Worked

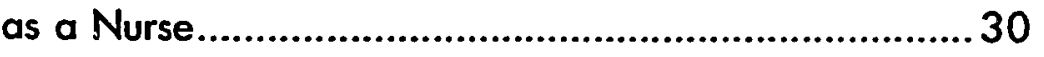

3. Frequency Distribution

of Amount of Exercise................................................33

4. Cross-tabulation of Level

of Frustration and Group.............................................. 35

5. Cross-tabulation of Level

of Overload and Group ...............................................36 


\section{List of Figures}

Figure

1. The Pelvic Tilt Method of Liffing with a Straight Back.................................................... 15

2. The Method of Liffing with

Normal Lordosis Curvature...........................................16

3. Histogram of Weight

by Height and Age...................................................... 32 


\section{Chapter 1 \\ INTRODUCTION}

The problem of back pain in the nursing profession and sociely in general is increasing. Eighty percent of the population will have a significant back problem at some point in their life (Frymoyer, Pope, Costanza, Rosen, Goggin, \& Wilder, 1980). The price to society, in terms of lost work days and treatment costs, amounts to an estimated $\$ 25-\$ 56$ billion annually in the United States alone (Gates, 1988). More money is spent on treatment for back pain by health care medical consumers in the 30-60-year range than on any other ailment (Girdano \& Dusek, 1988). Many of these back injuries can be prevented by maintaining the spine in its normal alignment through conditioning of the musculature, specifically the muscles of the back and abdomen (Girdano \& Dusek, 1988). One effect of conditioning the muscles would be to reduce chronic muscle tension. A stressful condition causes the muscles to contract tightly in response to tension. "When an event is perceived as stressful, the muscles become active and are ready for movement....Pain may be the result of ischemia of the tissues that are chronically tense" (Girdano \& Dusek, 1988, p. 295).

Owen and Damron (1984) suggest that a sense of stress overload, which in turn triggers a sense of frustration, stimulates a systemic reaction within the body that increases the potential for muscle strain. Their article was based upon the research reported by Owen in her doctoral dissertation (1982). A more succinct version of this research appeared in Rehabilitation Nursing at a later date (Owen, 1986). The purpose of Owen's study was to determine the relationship of selected personal characteristics in a population of back-injured and non-backinjured hospital nursing personnel. One of Owen's objectives was "to find out if 
there are differences in selected life-style characteristics between back-injured and non-back-injured hospital nursing personnel" (Owen, 1982, p. 2). Life-style characteristics included factors such as nutrition, exercise, smoking, and coping with stress. As Owen looked specifically at the stress component, she identified eight factors which comprised the index of stress: adaptation, frustration, overload, deprivation, nutrition, self perception, type A behavior, and anxious reactivity (Owen, 1982). Vulnerability to the two stress factors of frustration and overload were positively associated with back injury. Owen concluded that there is a need "to reduce the feelings of stress in the hospital nursing personnel" (Owen, 1982, p. 160).

Based upon Owen's research, this study was designed to explore the difference between two groups of nursing personnel, a back-injured and a nonback-injured group, in their response to the two variables of frustration and overload. It was expected that the original findings of the back-injured group being more vulnerable to frustration and overload would be supported, which would then add strength to her recommendations.

The Problem and Research Question

The problem addressed in this research was the lost worktime, personal suffering and costs caused by back injuries among nursing personel. This study examined how back-injured and non-back-injured nursing personnel from an acutecare teaching hospital responded to the stress factors of frustration and overload. The research question was: Is there a significant difference in frustration and overload scores between a back-injured and non-back-injured group of nursing personnel? 
Hypotheses

This study contained two null and two alternative hypotheses:

1. There is no difference in scores on the frustration questionnaire between back-injured and non-back-injured nursing personnel.

1a. Scores from nursing personnel in the back-injured group on the frustration questionnaire will be higher than scores from nursing personnel in the non-back-injured group.

2. There is no difference in scores on the overload questionnaire between back-injured and non-back-injured nursing personnel.

2a. Scores from nursing personnel in the back-injured group on the overload questionnaire will be higher than scores from nursing porsonnel in the non-back-injured group.

\section{Purpose and Need}

According to the National Institute for Occupational Safety and Health, back injuries account for almost half of the worker's compensation cases within the area of musculoskeletal disorders (National Institute for Occupational Safety and Health [NIOSH], 1985). Society must place a greater importance on the prevention of back pain. Besides pain, the single most common complaint in back injury victims is fatigue (Sheahan, 1982). Fatigue is also a common complaint in persons suffering from too high a level of stress. This is in accord with Hans Selye's General Adaptation Syndrome; the third and final stage is exhaustion, whereupon acquired adaptation is lost (1982).

The number of people over the age of 60 is increasing at a faster rate than the general population ("Global Population," 1988). As the population grows older, the work base will shrink, making good health and injury prevention within the working base of the population an even greater necessity. The treatment of back pain is 
difficult, and the long-term success rate is poor (Girdano \& Dusek, 1988). The key lies in prevention of this debilitating condition--back pain. By taking two of Owen's significant findings and testing them in a similar environment, it was expected that this research would provide more information about the problem of back injury in nursing personnel.

\section{Definition of Terms}

The following terms were defined for use in this research:

1. Nursing personnel: A registered nurse (RN), licensed vocational nurse (LVN), or nursing assistant (NA), employed in a large, acute-care hospital.

2. Back-injured nursing personnel: A person who has a record of a back injury during the past year.

3. Non-back-injured nursing personnel: A person who has neither a record nor personal history of a back injury during the past year.

4. Frustration: The inhibition of desired behaviors and goals caused by the inability to complete given assigned or desired activities.

5. Overload: A level of demands that exceeds the capacity to process or comply; an overstimulation caused by such factors as a high activity level and more demands being placed upon the nurse's time than can be met.

6. Back injury: Pain.or ache in the cervical, thoracic, lumbar, or sacral areas of the back.

\section{Research Design}

This study was designed to examine the hypotheses that frustration and overload scores are high among back-injured nursing personnel. The design used was descriptive survey research. Descriptive research serves the purpose of raising research questions for the purer forms of research (Polit \& Hungler, 1987). 
The population studied was a convenience sample of 72 current nursing personnel of a 402-bed acute-care teaching hospital in the western United States. There were two groups of 36: One was back-injured and the other was non-back-injured. The information was gathered from the sample groups through mailed questionnaires which included items on frustration, overload, and demographics. Three questionnaires were used. The two questionnaires on frustration and overload were designed by Girdano and Everly (1979, pp. 62, 67-8). These two instruments were found to be reliable and valid by Owen (1982). The third, the General Information Sheet, was a demographic questionnaire designed by the researcher (see Appendix $A$ for the research instruments).

Analysis of the data was done using Minitab (Pennsylvania State University, 1972), a general purpose data analysis software package (Ryan, Joiner, \& Ryan, 1982). The frustration and overload questionnaires were analyzed by taking the raw scores and using the Mann-Whitney $U$ statistic to examine the difference between the two groups. This nonparametric test was chosen for data analysis because the resulting groups were small, with 8 in the back-injured group and 10 in the non-back-injured group. Descriptive data is presented through a cross-tabulation of levels of frustration, overload, and group (back-injured and non-back-injured). The chi-square statistic was applied to assess whether there was a relationship between level of frustration, overload and group. The demographic questionnaire was analyzed using descriptive statistics such as frequency distributions, percentages, crosstabulations, histograms, and the chi-square statistic where applicable.

\section{Scope and Limitations}

The scope of this study was narrow in its focus since the researcher concentrated on a small part of a larger study and used it as a basis for further 
research. Since this was a highly specialized area of study, the scope was limited which thereby constrained the ability to generalize to a larger population. The following were limitations of this study:

1. Given the retrospective method used to select the back-injured group, it was not possible to randomly select the sample. Hence the resulting data should not be construed as representative of a larger population, another period of time, or a different setting.

2. The sample was taken from the researcher's place of work, thereby possibly adding bias to the results.

3. The use of mailed questionnaires was limited to respondents who were accessible and cooperative, and depended upon their ability to complete and return the survey materials.

4. There was no assurance that the addressee was actually the one who completed the three questionnaires.

5. A small sample size would make the statistics less stable. Hence, it was recognized that the findings would have limited generalizability, and there would be decreased confidence in the reliability of the results. For this reason, a non-parametric lest was used to increase the power of the results. 


\section{Chapier 2}

\section{CONCEPTUAL FRAMEWORK AND RELATED LITERATURE}

\section{Conceptual Framework}

The conceptual framework selected for this study was the cognitive appraisal theory developed by Lazarus and colleagues (Lazarus \& Folkman, 1984; Lazarus, Kanner, \& Folkman, 1980). This theoretical understanding of the effects of psychological stress on health provides a coherent integration and orientation in the field of psychological stress. The theory had its beginnings in 1966 when Lazarus suggested that stress was an organizing concept for the understanding of phenomena in human adaptation (Lazarus, 1966). Hence, stress is more than a variable; it can be compared to a rubric made up of many variables and processes. The cognitive appraisal theory focuses on the individual's cognitive appraisal of the personenvironment relationship. Lazarus defines cognitive appraisal as "an evaluative process that determines who and to what extent a particular transaction or series of transactions between the person and the environment is stressful" (Lazarus \& Folkman, 1984, p. 19). A transaction can be defined as an encounter. Coping can be defined as the process of the individual's management of the demands of the person-environment which are appraised as stressful.

Jean $E$. Johnson (1989) recently reviewed the cognitive appraisal theory. She posits that the cognitive appraisal theory examines the relationship between informational interventions and coping with stressful experiences associared with physical illness. Johnson (1989) writes that the cognitive appraisal theory explains "why information interventions might facilitate coping with physical illness" (p. 48). The example given was of the influence of preparatory information in a study of patients receiving radiation therapy. She proposes that the information influenced their appraisal of the experience, thereby decreasing feelings of ambiguity and reducing 
appraisals of threat. Threat appraisai was measured by negative mood. An individual's cognitive activity can be defined by learning, memory, perception and thought. These are critical facets in the individual's emotional response pattern. Lazarus and his colleagues have continued to refine and test the cognitive appraisal theory. In a recent work, the Specificity Model of Illness was presented (Lazarus \& Folkman, 1984, p. 219). This model describes the person-environment relationship, that is, how the individual's appraisal results in a specific emotion and/or coping method. The specific emotion results in a particular pattern of physiological disturbance which can then lead to a specific illness. Alternatively, the coping method can result directly in the specific illness. This can be described as the personenvironment relationship. The consequent appraisal results in either coping or a specific emotion. If it results in coping, then a specific illness can occur.

Only a portion of the cognitive appraisal theory has been utilized as a conceptual framework for this study. As this study contains no measurement of emotions, the portion of the model concerned with specific emotion was not applicable.

Essentially, the Specificity Model of Illness is a paradigm of the cognitive appraisal theory. An individual's ability to cope can be viewed as a mediation factor. In this definition of stress, a mediation factor is a psychological process which is operative and is more than just a physiological expression of the autonomic nervous system and hormonal change.

If the encounter is stressful, it can be appraised by the individual in one of three ways: (a) harm-loss, (b) threat, or (c) challenge. In a harm-loss appraisal, injuries are perceived as having already occurred. With threat, injuries are anticipated. However, in a challenge appraisal, the sifuation is viewed as a means of anticipated gain, 
mastery, or growth. While harm-loss lies in the past, both threat and challenge lie in the future and are distinguished primarily by the individual's perception of the situation.

Upon appraising an encounter as stressful, the secondary form of cognitive appraisal evaluates options and coping resources available to the individual. This secondary appraisal is potentiated by stress as "coping efforts are required to overcome, tolerate, or accept the actual or potential harmful outcome" or to achieve the gain if it is a challenge (Lazarus, Kanner, \& Folkman, 1980, p. 193). The secondary appraisal "may be even more important than the occurrence of the stressful event itself, for the person's evaluation of the adequacy of his or her resources will in a large part determine whether, for example, he or she feels threatened, challenged, or hopeful" (Lazarus, Kanner, \& Folkman, 1980, p. 193).

The appraisal of the environment was measured by the questionnaires on frustration and overload. Coping was measured by the presence or absence of a sustained back injury. Frustration and overload, as defined in this study and within the conceptual framework of Lazarus, are harmful transactions with the environment. The portion of the Specificity Model of Illness used describes the person-environment relationship whereby an individual's appraisal results in a coping level, and then finally leads possibly to a specific illness. Thus an individual's ability to cope is a mediation factor, a psychological process which is operative in this definition of stress, and is more than just a physiological expression of the autonomic nervous system and hormonal change.

The application of the portion of the Specificity Model of Illness to this study was operationalized by giving Questionnaire A (which measured frustration), and Questionnaire B (which measured overload), to a back-injured and a non-back-injured group of nursing personnel matched for environment. The individual scores provided a measure of each respondent's appraisal of his/her individual level of frustration and 
overload. The possibility of an illness or injury was expected to increase as an individual appraised the situation as increasingly stressful.

\section{Related Literature \\ Introduction}

According to the cognitive appraisal theory of Lazarus, a back injury can be viewed as the specific illness resulting from the appraisal of, and coping with, the person-environment relationship. The key to prevention of back injuries lies in comprehending the nature of the "specific illness," which in this study is the costly and painful problem of back injury. This encompasses first examining the incidence of back injuries in the general population and then specifically in nursing personnel. Second, the person-environment relationship was examined as the demographics and possible causes of back injury were presented. Third, probable informational interventions were investigated as the current educational practices on prevention of back injury in the literature were reviewed. Finally, the stress concepts of frustration and overload (the measurements of coping) and the concept of coping conclude this section.

\section{Incidence of Back Iniuny}

Incidence of back injury in the general population is a problem of great magnitude given that as many as $85 \%$ will experience this problem at some time (Spengler, Bigos, Martin, Zeh, Fisher, \& Nachemson, 1986, p. 241). Back injuries account for $20 \%$ of all work-related injuries, and 2 million Americans are unable to work because of back problems (Sheahan, 1982). Another source places actual incidence as affecting from $50 \%$ to $80 \%$ of the population (White \& Gordon, 1982). A more recent source suggests that it is as high as $85 \%$ (Bigos, Spengler, Martin, Zeh, Fisher, Nachemson, \& Wang, 1986).

The economic implications of back injury are immense. Annually in the United States of America, 14 billion dollars are spent on treatment and Worker's 
Compensation for back pain (White \& Gordon, 1982). The National Institute for Occupational Safety and Health is the United States Public Health service agency with primary responsibility for research concerning the prevention of work related injuries. When a priority list was established by NIOSH of the 10 leading occupational injury and illness problems, disabling back pain was identified as one of the top 10 problems (Miller \& Myers, 1983). In a recent article reviewing the costs of back pain in industry, Snook (1988) puts the annual costs at 16 billion dollars per year. "An investment in the workplace to reduce back pain costs can be a wise business decision--to say nothing about the reduction in human suffering" (Snook, 1988, p. 5). He also concludes that $10 \%$ of the cases account for $78 \%$ of the costs, and $25 \%$ of the cases account for $93 \%$ of the costs. In terms of lost time, Andersson acknowledged in an editorial the need to identify work factors related to back pain: "More people are off work because of back pain than because of any other disease or injury" (Andersson, 1981, p. 52).

Incidence of Back Injury Among Nursing Personnel

Incidence of back pain among nursing personnel tends to run higher than the general population. One study demonstrated that $87 \%$ of the riursing population experienced one or more episodes of low back pain (Arad \& Ryan, 1986). The study concluded that "an unacceptably high rate of back pain and risk of future disabiliy" exists among nursing personnel (Arad \& Ryan, 1986, p. 44). A survey of 3,912 nurses in Great Britain suggested that 750,000 working days were lost annually because of back injuries (Stubbs, Buckle, Hudson, Rivers, \& Worringham, 1983). Another study by Magora and Taustein (1969) revealed that nurses have the second highest incidence of back pain, the highest being found in heavy industry workers. In addition, their study showed that while most subjects developed back pain in their thirties and forties, nurses and heavy industry workers had an earlier age of onset. A more recent study by 
Greenwood (1986), conducted over a 4-year period in health care facilities, concurs, citing a back pain occurrence of $21.6 \%$ in heavy industry workers and $16.8 \%$ in nursing personnel. Greenwood also found that $57 \%$ of the injuries occurred in persons under the age of 25-years (Greenwood, 1986). Cust, Pearson, and Mair (1972) found the 21-25-year age group to be when nursing personnel would first experience back pain. In their research they also noted that another peak in back injuries occurred in nursing personnel between the ages 46-50-years (Cust, Pearson, \& Mair, 1972). Gates found that $52 \%$ of the reported back injuries occurred in nursing personnel under the age of 30-years (Gates, 1988).

Lortie (1987), in a study of a group of nursing assistants employed in a geriatric hospital, collected accident data from 1973 through 1982. Accidents caused by a muscular effort applied to a handling operation were studied. Quantitative data, such as date and time of accident, interval between the claim and beginning of absence, and duration of absence, was collected. Back injuries occurred during half of these accidents. Absences from work occurred in $59 \%$ of the accidents; back injuries were associated with $56 \%$ of these absences (Lortie, 1987). It was observed that the sooner an employee took a leave of absence following an accident, the shorter the duration of absence. The night shift had a higher incidence of back injuries. September through November accounted for $46 \%$ of the accidents. Another factor affecting incidence was the suggested nonreporting of back injuries. Group interviews were conducted during which past accidents never before reported were spontaneously mentioned. Lortie surmises that nonreporting of back injuries is an underestimated phenomenon.

\section{Demographics}

The demographics of back pain implicated the following risk factors for back pain: Male sex, a positive family history of back pain, chronic cough and bronchitis, participants of golf, bowling or baseball, and upper social-class females. Symptoms 
such as lethargy and depression, and health habits such as deficient diet, inadequate rest, and lack of exercise were cited in the literature (Sheahan, 1982). Mandel and Lohman (1987) surveyed nursing personnel regarding demographics, medical history, exercise, and work variables, and concluded that factors unrelated to work, such as frequent aerobic dance exercise which involve twisting and heavy impact, may be more important in the development of back injury than previously thought. It is possible that the physical stress of certain leisure activities could be harmful to the back. Another study suggested that back pain can lead to depression, anxiety, fear and preoccupation with health (White \& Gordon, 1982).

An examination of the demographics among nursing personnel were studied by Owen (1982). Four demographic variables--age, type of work environment, existence of a previous back injury, and early onset of back problems among family members-were examined. Increased age, working on units requiring heavy lifting, family members with low back pain, and early onset of the back pain by these family members were all found to be significant risk factors for back injury among nurses.

\section{Causes}

The multifactorial nature of a back injury makes delineating the causes difficult. Owen and Damron (1984), reported that the variables most closely associated with back pain were a sense of frustration and overload, lack of muscle flexibility, poor proprioception, difference in leg length, and smoking. Another study reported that causes included lack of basic liffing skills, failure to utilize the patient's ability to help, failure to raise beds, and ward environments that lack space (Stubbs, Rivers, Hudson, \& Worringham, 1981). A later study showed that 1 in 6 (159 per 1000 at risk) ascribed the beginning of back pain to a patient-lifting incident (Stubbs, Buckle, Hudson, Rivers \&Worringham, 1983). 


\section{Educational Interventions and Prevention}

Current education practices concerning the prevention of back injury are presently in a state of transition, as many of the standard axioms of "good body mechanics" are being empirically tested. It has been demonstrated through the use of muscle strength dynamometers, for example, that muscles of the lower back are extremely strong rather than weak as was previously thought (Hebert \& Miller, 1987). The traditional method of correct body mechanics for lifting has been to use the straight back, bent knee method (as opposed to the rounded back method). The individual was to use a pelvic tilt, contracting the abdomen and tucking in the buttocks to flatten out the lower back (see Figure 1). "The pelvic tilt position also sets up a neurological reflex that inhibits these muscles as they are trying to contract to protect the ligaments, the facet joints, the discs and themselves from excessive loading stresses" (Hebert \& Miller, 1987, p. 57). Hence, through the use of biomechanical analysis, it was shown that the pelvic tilt requires these muscles to work from a weakened position where they are overstretched and unable to withstand the trunk bending forces of lifting. Now the recommended technique is to lock the back in a position of normal lordosis curvature (see Figure 2). This is the technique used by Olympic class weightliffers; back injuries are rare among this group (Hebert \& Miller, 1987).

Another study utilized a biomechanical device with a microprocessor unit, the lifting stress calculator (LSC), to determine "the optimum method of lifting given the anthropometry and clinical symptoms, and the physical characteristics of the load" (Parnianpour, Beijani \& Pavlidis, 1987, p. 331). The LSC performs computational and interface functions after personal anthropometric, clinical data, and load characteristics are entered through a keyboard. Parnianpour (1987) recommended the use of the LSC in training and workplace design. Their findings concluded that there was no one simple, safe way of lifting. 
15

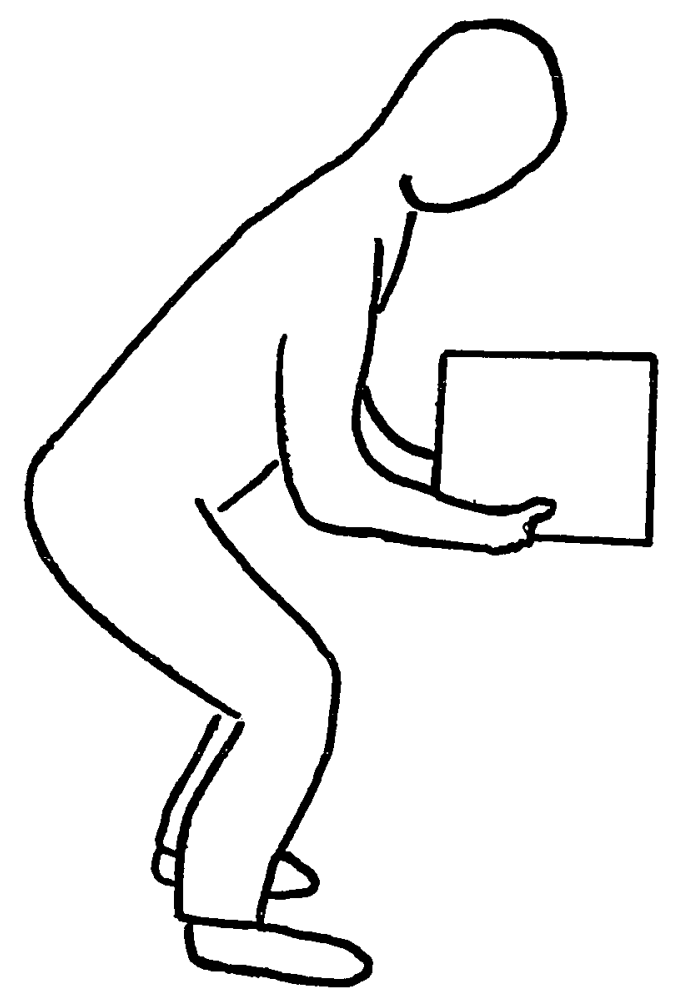

Figure 1. The Pelvic Tilt Method of Lifting with a Straight Back. 


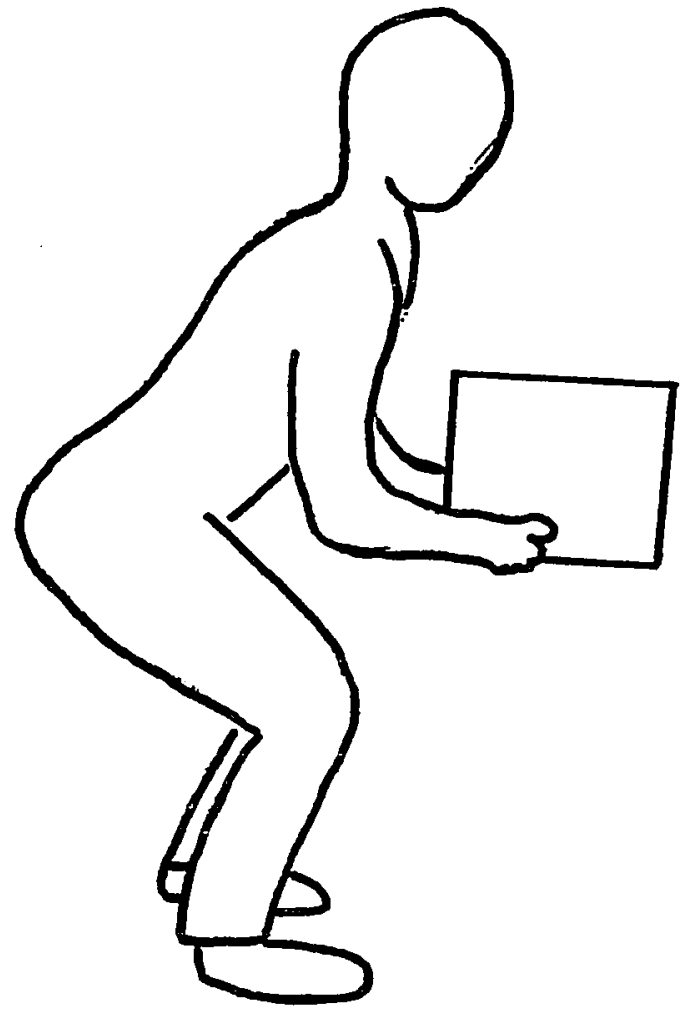

Figure 2. The Normal Lordosis Curvature Method of Liffing. 
Aside awareness of correct body mechanics, which is the foundation of injury prevention, other approaches include stress management, physical conditioning and ergonomic counseling. Ergonomics has to do with designing the job to fit the capabilities of the worker. Webster's Ninth New Collegiate Dictionary (1988) defines ergonomics as "an applied science concerned with the characteristics of people that need to be considered in designing and arranging things that they use in order that people and things will interact most effectively" (p. 422). In terms of back injury prevention, ergonomic counseling organizes the work to fit the individual's body capability.

Actual application of a back injury prevention training program was conducted in a large corporation (Tomer, Olsen \& Lepore, 1984). The approach used was to identify common work practices that could be modified. This study included a component on stress management which examined personal and occupational factors causing stress. It was thought that by learning how to interrupt the stress cycle, workers would experience a decrease in back pain. This program resulted in a $76 \%$ reduction in the average cost of a back injury claim. Another study examined the effects of physical training and ergonomic counseling upon two different groups of workers (Dehlin, Berg, Andersson \& Grimby, 1981). Their psychological perception of work and the subjective assessment of back pain was compared. Only the physical training group showed a significant decrease in back injuries.

\section{Stress: Frustration and Overload}

A large study linking stress to back injury revealed that patients with back pain had more emotionally stressful occupations and reported increased episodes of anxiety and depression (Frymoyer, Pope, Costanza, Rosen, Goggin \& Wilder, 1980). This supports the idea that increased stress may be positively related to back injury. Owen and Damron (1984) suggested that a sense of stress overload, which in furn triggers a 
sense of frustration, stimulates a systemic reaction within the body that increases potential for muscle strain. Gates (1988) concurs as she reports that both personal and work-related stress can result in back pain. The causal link theorized is that emotional stress leads to shortening and tightening of the back muscles. These tight, contracted muscles decrease spinal flexibility, which can result in a back injury (Gates, 1988).

The questionnaires on frustration and overload used in this study were originally developed by Girdano and Everly (1979). Causes of frustration as stress include overcrowding, prejudice and discrimination, socioeconomic elements, and large bureaucratic structures. The results of frustration stress are "reactions which are expressed in the forms of anger, aggression, increased sympathefic nervous activity, and an increased incidence of mental trauma" (Girdano \& Everly, 1979, p. 66).

There are four major types of overload described: (a) time pressures, (b) excessive responsibility, (c) lack of support, and (d) excessive expectations from those around you. When work places demands beyond one's resources, stress in the form of overload occurs. Since each person internalizes events differently, levels of psychosocial stress vary (Girdano \& Everly, 1979).

Another aspect of the stress process is the concept of coping. This concept was explored in depth in "The Structure of Coping" by Pearlin and Schooler (1978). Coping was defined as "the things people do to avoid being harmed by life-strains" (Pearlin \& Schooler, 1978, p. 2). Coping was acknowledged to have other conceptual meanings such as mastery, defense and adaptation. Life-sirains were defined as conflict, frustrations and threats. While general psychological resources, that is, the behaviors, cognitions and perceptions utilized in problematic situations, represent part of an individual's personality, coping responses represent the concrete efforts of an individual to deal with life-strains. If was argued that when coping fails to 
change the situation, "the stressful impact of the problem may nevertheless be buffered by responses that function to control the meaning of the problem" (Pearlin \& Schooler, 1978, p. 6). An experience may be perceived as either threatening or harmless depending upon the individual's perception and how one cognitively appraised the situation; Lazarus (1966) was cited by Pearlin and Schooler (1978) for this concept. "By cognitively neutralizing the threats that we experience in the life-situations, it is possible to avoid stresses that might otherwise result" (Pearlin \& Schooler, p. 6). This quote captures the essence of what this present research on frustration and overload in a back-injured group and a non-back-injured group purports to accomplish.

A number of specific devices an individual could use for coping were given (Pearlin \& Schooler, 1978). One device was making positive comparisons by viewing a situation as being an improvement compared to hardships of the past or some other frame of reference. Selective ignoring was another device. To selectively ignore, the individual focuses on some positive aspect of a situation, anchors on what is gratifying, and succeeds in trivializing the unpleasant aspects of the situation.

According to Pearlin and Schooler (1978), four characteristics which had close statistical associations with coping were sex, age, education and income. Generally, women respond to stress in a manner likely to result in more stress. In terms of age, coping was more balanced. While youth were more likely to be self-denigrating, they were more apt to have a sense of mastery. Older individuals cope by the use of selfreliance and utilization of the practice of selective ignoring. In terms of education and income, the self-attitudes of mastery and self-esteem were both prominent factors. It was suggested that perhaps some "people have better access to the more effective coping techniques because of their privileged positions." "Privileged positions" refers to their high level of education and income (p. 17). Another interesting finding was that 
an individual's coping efforts were least effective when dealing with the impersonal problems found in their occupation.

\section{Summary}

The literature indicates that back injury is a significant problem for which the best cure is prevention through sound ergonomic practices and increased selfawareness. Many of these studies have been retrospective studies; there is a need for more conclusive prospective studies. Also not enough studies have been replicated to conclude which factors are the most relevant. 


\section{Chapter 3}

\section{THE METHOD}

\section{Research Design}

Nonparametric statistics and other techniques were applied to responses from survey instruments to determine the differences between two groups of nursing personnel, a back-injured and a non-back-injured group, in their response to the two variables of frustration and overload. The null and alternative hypotheses are:

1. There is no difference in scores on the frustration questionnaire between back-injured and non-back-injured nursing personnel.

1a. Scores from nursing personnel in the back-injured group on the frustration questionnaire will be higher than scores from nursing personnel in the non-back-injured group.

2. There is no difference in scores on the overload questionnaire between back-injured and non-back-injured nursing personnel.

2a. Scores from nursing personnel in the back-injured group on the overload questionnaire will be higher than scores from nursing personnel in the non-back-injured group.

\section{The Setting and the Sample}

The subjects were employees from a 402-bed acute-care teaching hospital in the western United States. The facility serves primarily veteran clients. Types of units include general medicine and surgery, neurosurgical, respiratory, telemetry, oncology, psychiatry (unlocked), alcohol and drug rehabilitation, an ambulatory care area (i.e., a non-emergency room) and an intensive care unit (ICU). Team nursing is practiced in most units (excluding psychiatry and the ICU).

The population was a convenience sample composed of 72 nursing personnel: RNs, LVNs, and NAs employed in an acute-care hospital. The sample was divided into 
two groups of 36, a non-back-injured and a back-injured group. The selection of the non-back-injured group was done using a simple stratified sampling technique (Leedy, 1985). The selection of the back-injured group was limited by the number of documented back injuries from October 1, 1987 through September 30, 1988.

The non-back-injured subjects were selected from the population of nursing personnel who were employed on the hospital wards where the back injuries had been reported. The names of all nursing personnel employed on these wards were obtained on September 30, 1988 from the ward rosters kept in the Nursing Department. The names of the back-injured subjects were deleted from these rosters prior to selecting the sample for the non-back-injured group.

The ward rosters listed nursing personnel alphabetically according to licensure. The subjects were matched with the back-injured group for licensure and number of back-injured subjects from each ward. The "Table of Random Numbers" (Runyon \& Haber, 1984, p. 451-454) was used in selecting the subject's names for the non-back-injured group. For example, there were five back-injured RNs from ICU. These names were removed from the ICU roster. Of the remaining names, five were randomly selected. The non-back-injured subjects were nursing personnel with no documented report of a back injury.

The back-injured group consisted of nursing personnel who had filed a back injury report during the past 12 months with the Personnel Office. Copies of all injury reports are sent to the Nursing Safety Commiltee. The purpose of the Nursing Safety Committee is to evaluate present practices and make recommendations to improve hospital safety for patients and staff. All injury reports are tabulated as to type, frequency, and percentage, and then analyzed for trends. Based upon this analysis, recommendations are made in a monthly report which goes to the units, the executive nurse and the Hospital Safety Committee. 
The names of the back-injured nursing personnel were obtained by the researcher from the chairperson of the Nursing Safety Committee. This was possible because the researcher is a member of the Nursing Safety Committee and has also functioned as a nurse educator for back-injury prevention and body mechanics within the Nursing Department. Had the researcher not been a member of the Nursing Safety Committee, it would have been necessary to have a member contact all the back-injured nurses to obtain permission to give their names to an outside researcher. Instruments

Three instruments were used in this study (see Appendix A for the research instruments). One instrument was the general information questionnaire developed by the researcher to collect demographic data. The other two instruments were the frustration and overload questionnaires developed by Girdano and Everly (1979). The reliability and validity of the questionnaires for frustration and overload were first examined by Owen (1982) who performed a reliability analysis on the two variables (frustration and overload) using the reliability statistic, Cronbach's Alpha. The alpha was .78 for frustration and .76 for overload (p. 56).

Additional documentation of the reliability and validity of the frustration and overload instruments was given by Owen. Owen (1982) referred to a personal communication with Everly in 1981 where he indicated that his research had shown that the frustration questionnaire "correlated well with general anxiety (.7)" and the overload questionnaire "correlated well with general anxiety (.70)" (p. 55).

Frustration was measured by the frustration questionnaire (see Appendix A for "Self-Assessment Questionnaire A"). This instrument has 10 items measured on a Likert scale of four choices ranging from "almost always true" to "almost never true." Items 1 and 10 are reverse scored. The instrument was scored by summing the 10 items 
according to a pre-determined weight of 1.4 points (see Appendix A for the scoring of the instruments).

Overload was measured by the overload self-assessment questionnaire (see Appendix A for "Self-Assessment Questionnaire B"). This instrument has ten items measured on a Likert scale of four choices ranging from "almost always true" to "almost never true." The iristrument was scored by summing the 10 ifems according to a predetermined weight of 1-4 points. For each questionnaire, the total possible score was 40-points and the lowest possible was 10-points. Raw scores were used to analyze the data.

Permission to use the instruments was obtained from the Permissions Department at Prentice-Hall, Inc. (Englewood Cliffs, New Jersey) as Prentice-Hall owns the copyright on the book Controlling Stress and Tension: A Holistic Approach by Girdano and Everly (1979, pp. 62, 67-8). The instruments were originally published in this book (see Appendix $C$ for the permission letter).

Approval of this study was obtained from the Human Subjects and Scientific Review Committees of the participating institution during August of 1988. During the same month, the proposal was approved by the Committee for the Protection of Human Subjects at San Jose State University (see Appendix D).

The demographic profile of the population was obtained through the General Information Sheet (see Appendix A for "General Information Sheef"). Information gathered included licensure, length of time as nursing personnel, family history of back pain, employment (full or part time), marital status, sex, educational preparation, age, height, weight, and activity level outside of work (hours of exercise). Participants were also asked if they had sustained a back injury during the past year and if it was documented at work. (This was a means of screening out any participants in the non-back-injured group who had an unreported back injury.) If the answer was "yes" to 
the back injury question, then they were asked if they have changed anything in their life since the injury.

\section{Procedure}

Initial contact with both groups was made through the mail to ensure privacy. The three survey instruments, Questionnaires A, Questionnaire B, and the General Information Sheet, were mailed along with the cover letter and informed consent (see Appendix B for the cover leter and informed consent). An addressed, stamped envelope was enclosed to allow for the anonymous return of the three instruments. $A$ copy of the informed consent was given to the subjects for their information and record. Every effort was made to ensure participant anonymity. The survey instruments were not numerically coded; however, the return envelopes were coded to distinguish the back-injured group from the non-back-injured group. As each return envelope was opened, participants were given a subject and a group identification number.

Within 10-15 days after the questionnaires were mailed, a letter reminding respondents to return the questionnaires was to have followed; however, a clerical oversight precluded the reminder. The returned questionnaires were kept secured and finally destroyed after data were tabulated.

\section{Data Collection}

Twenty-four sets of questionnaires, 13 from the back-injured group and 11 from the non-back-injured group, were returned. This was a $33 \%$ return rate. Five subjects had to be dropped from the back-injured-group because of incomplete questionnaires. Another subject was dropped from the non-back-injured group because the respondent had sustained an undocumented back injury. This reduced the usable return rate to $25 \%$. Eight of the usable questionnaires were from the back-injured group and 10 were from the non-back-injured group. 
Data Analysis

Data from Questionnaires A and B were analyzed using the MannWhitney $U$ test. "The Mann-Whitney $U$ test is used to determine whether two sets of data based on two independent samples came from the same population" (Spatz \& Johnson, 1984, p. 282). It is the nonparametric counterpart of the parametric t-test. In the case of small samples, as in this study, or a possibly skewed distribution of the sample, it is generally considered a more appropriate test. The alpha level was set at .05 .

In addition to the test for significant differences between groups, a crosstabulation of levels of frustration, overload and group was done and a chi-square statistic was computed to test "whether or not a significant difference exists between the observed number of cases falling into each category, and expected number of cases, based on the null hypothesis" (Runyon \& Haber, 1984, p. 362). The demographic questionnaire was analyzed descriptively through frequency distributions, percentages, and cross-tabulations. A chi-square statistic was also computed between group and age, group and exercise, group and years worked as a nurse, and, finally, group and deviation from normal weight for height and age. This was obtained by comparing the weights of subjects by height and age in each group to the "Average Weight of Americans by Height and Age" table (The World Almanac, 1989, p. 823). The Minitab computer statistical package was used for all computations (Pennsyivania State University, 1972). 
Chapter 4

\section{ANALYSIS AND INTERPRETATION OF DATA}

\section{Description of the Sample}

The analysis and interpretation of data in this study was based upon the sample of 18 nursing personnel. One group had a documented history of back injury $(n=8)$ and the other group was without back injury either documented or stated $(\underline{n}=10)$. Henceforth, the data will be referred to by percentages. The subjects studied were between the ages of 20-69 years. The median age for the back-injured group fell between $40-49$ years. A total of $62 \%$ of the back-injured group were in this age range. Of the remainder of the back-injured group, $25 \%$ were between 20-29 years and $12.5 \%$ were between $50-59$ years. The median age for the non-back-injured group was also between $40-49$ years. A total of $50 \%$ of the non-back-injured group were in this age range. Overall, the non-back-injured group was older, as $30 \%$ of the remainder were between $30-39$ years and $20 \%$ were between 60-69 years. Table 1 represents frequency of the subject's ages for each group (see Table 1). The chi-square statistic between group and age was not found to be significant, $X^{2}(4, \underline{N}=18)=7.875$, $p>.05$.

The age at which onset of back pain occurred was a demographic question asked of the back-injured group. Three of the subjects left this item blank on their questionnaires. Of the five responding, the age at initial onset of back pain ranged from $27-48$ years with a mean of $\mathbf{4 2 . 2}$ years.

An analysis of distribution of licensure found that the total sample $\underline{N}=18$ ) was comprised of $50 \%$ RNs, $39 \%$ LVNs, and $11 \%$ NAs. Breaking it down into groups, the back-injured group ( $\underline{n}=8$ ) was comprised of $50 \%$ RNs, $37.5 \%$ LVNs, and $12.5 \%$ NAs. 
Table 1

Frequency of Age and Group

\begin{tabular}{cccccc}
\hline Group & \multicolumn{5}{c}{ Age } \\
& $20-29$ & $30-39$ & $40-49$ & $50-59$ & $60-69$ \\
Back-injured & 2 & 0 & 5 & 1 & 0 \\
& $25 \%$ & $0 \%$ & $62.5 \%$ & $12.5 \%$ & $0 \%$ \\
Non-back-injured & 0 & 3 & 5 & 0 & 2 \\
& $0 \%$ & $30 \%$ & $50 \%$ & $0 \%$ & $20 \%$ \\
\hline
\end{tabular}

Note. No significant difference between groups $(\underline{2}<.05)$. 
The non-back-injured group $(\mathrm{n}=10$ ) was comprised of $50 \% \mathrm{RNs}, 40 \% \mathrm{LVNs}$, and $10 \%$ NAs.

The number of years employed as nursing personnel was between 1-10 years for $62.5 \%$ of the back-injured group. None of the back-injured nursing personnel had worked more than 35 years. In contrast, $80 \%$ of the non-backed-injured group had worked from 11 to greater than 35 years. Table 2 represents the frequency of years worked as a nurse for each group (see Table 2). However, the chi-square statistic between group and years worked as a nurse was not found to be significant, $X^{2}(5, \underline{N}=18)=4.838, \underline{p}>.05$.

Family history of back pain was a demographic question asked of each group. The two groups responded similarly with $60 \%$ of the non-back-injured and $62.5 \%$ of the back-injured group denying any family history of back pain.

Seventy percent of the non-back-injured and $87.5 \%$ of the back-injured group were married. The gender of $100 \%$ of the non-back-injured and $87.5 \%$ of the back-injured subjects was female. Employment status revealed that $75 \%$ of the back-injured group and $90 \%$ of the non-back-injured group were full-time employees.

Level of education by group revealed that the entire population $(\underline{N}=18)$ had at least some college-level courses. Twenty-five percent of the back-injured group were college graduates at the baccalaureate level. Thirty percent of the non-back-injured group were masters prepared.

The heights of the back-injured participants ranged from 62-69 inches. The median height was 63.69 inches. The heights of the non-back-injured participants ranged from 60-68.75 inches. The median height was 64.32. The weights for the back-injured participants ranged from 105-282 pounds. The median weight was 156.97 pounds. The weights for the non-back-injured paritcipants ranged from 


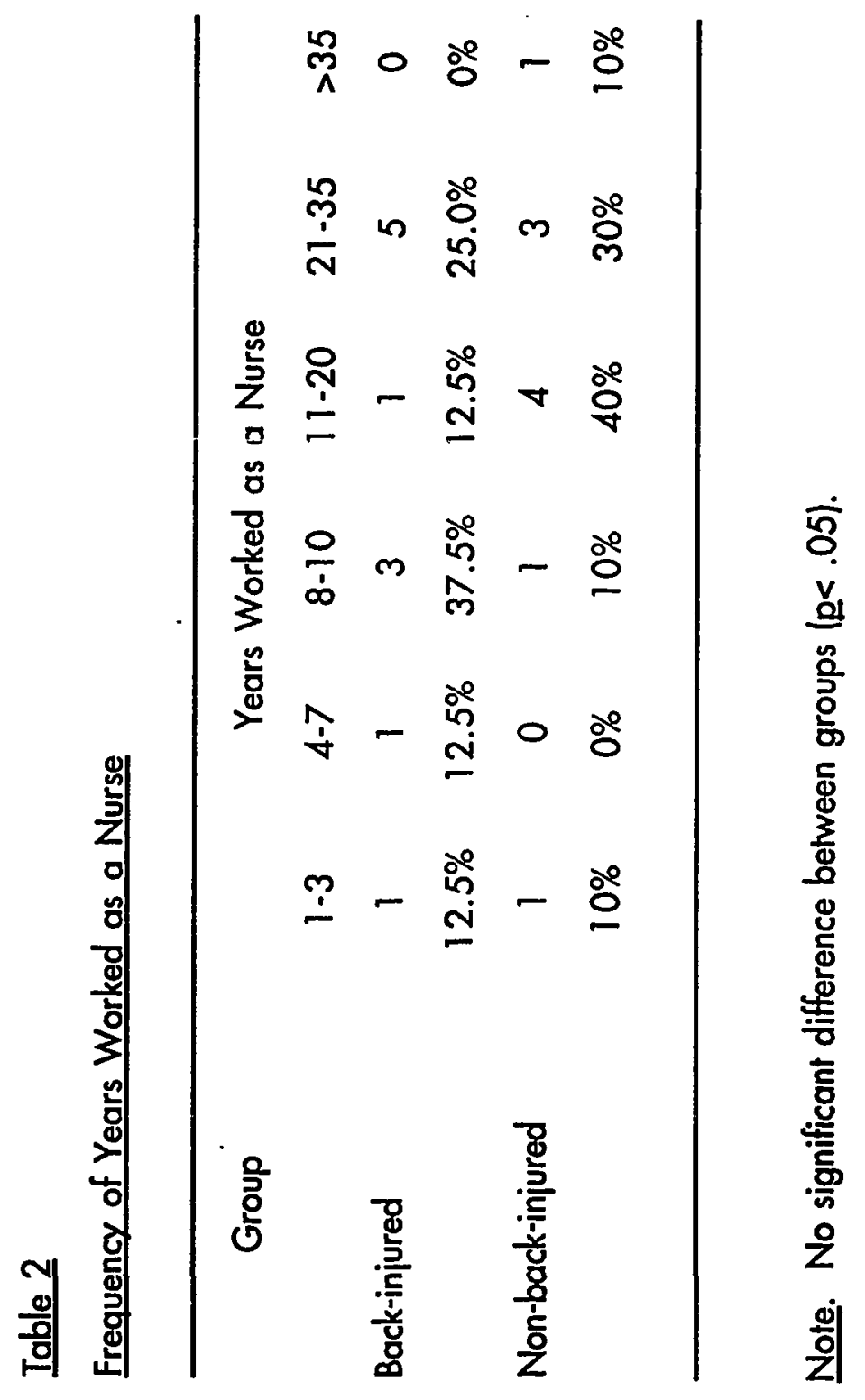


120-160 pounds. The median weight was 135.11 pounds. This was based on 9 responses; one subiect in the non-back-injured group left this item blank.

The weights of the participants of the two groups were compared to the "Average Weight of Americans by Height and Age" table (The World Almanac, 1989, p. 823). The back-injured group showed a much greater deviation from the normal weight by height and age found in the table. Their weights ranged from 19.5 pounds below normal to 109 pounds above normal. In contrast, the non-back-injured group ranged from 18 pounds underweight to only 11 pounds overweight. This data is graphically depicted by a histogram (see Figure 3).

The frequency of amount of exercise outside of work for each group is represented in Table 3. Seventy-five percent of the back-injured group exercise 1-2 hours per week. In contrast, $80 \%$ of the non-back-injured group exercise 3 or more hours per week. The chi-square statistic was found to be significant, $X^{2}(3, \underline{N}=18)=8.229, \underline{p}<.05$

Analysis

The frustration test scores for the back-injured and non-back-injured groups of nursing personnel $(\underline{N}=18)$ were analyzed using the Mann-Whitney $U$ statistic. The test was not significant at the .05 level $(p=.72)$. This study has failed to reject the null hypothesis of no difference in frustration scores between the back-injured and non-back-injured nursing personnel. The alternative hypothesis that scores from nursing personnel in the back-injured group on the frustration questionnaire were higher than scores from nursing personnel in the non-back-injured group was rejected.

The overload test scores for the back-injured and non-back-injured groups of nursing personnel $(\underline{N}=18)$ were analyzed using the Mann-Whitney $U$ statistic. The test was not significant at the .05 level $(p=.82)$. This study failed to reject the null 


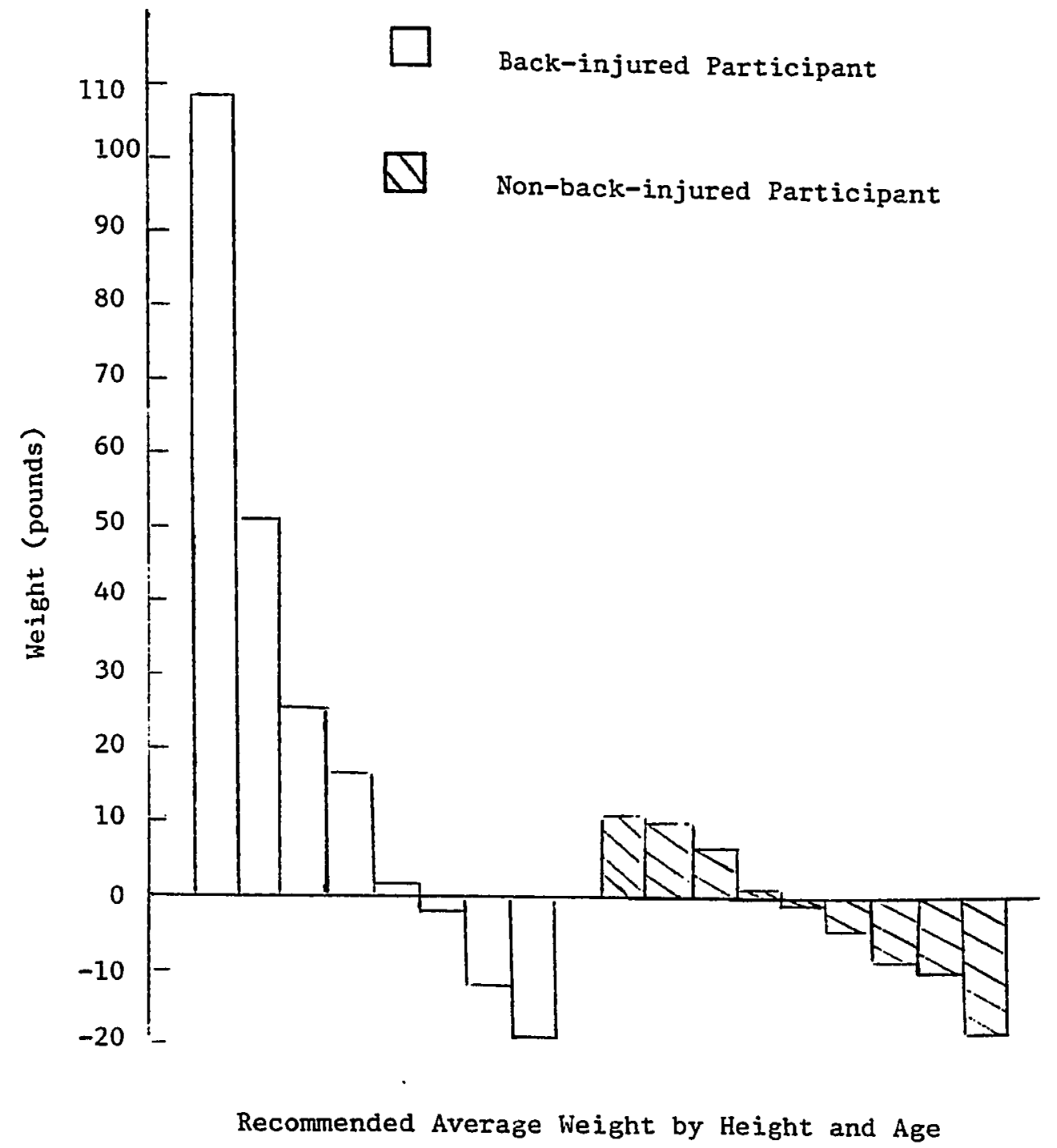

Figure 3. Histogram of Weight by Height and Age. 
Table 3

Frequency of Amount of Exercise

\begin{tabular}{ccccc}
\hline Group & \multicolumn{4}{c}{ Amount of Exercise } \\
& \multicolumn{4}{c}{ (Hours per Week) } \\
Back-injured & 0 & $1-2$ & $3-5$ & $>5$ \\
Non-back-injured & 0 & 6 & 2 & 0 \\
& $0 \%$ & $75 \%$ & $25 \%$ & $0 \%$ \\
& 1 & 1 & 7 & 1 \\
& $10 \%$ & $10 \%$ & $70 \%$ & $10 \%$ \\
\hline
\end{tabular}

Note. Significant difference between groups $(p<.05)$. 
hypothesis of no difference in overload scores between the back-injured and nonback-injured nursing personnel. The alternative hypothesis that scores from nursing personnel in the back-injured group on the overload questionnaire were higher than scores from nursing personnel in the non-back-injured group was rejected.

The highest possible score was $\mathbf{4 0}$ points and the lowest possible score was 10 points for both the frustration and overload questionnaires. Raw score totals for each questionnaire were used for analysis. A score of 10-20 points indicated low vulnerability to frustration or overload. A score of 21-26 points indicated average vulnerability to frustration or overload. A score of $27-40$ points indicated high vulnerability to frustration or overload.

The scores from the frustration questionnaire for the back-injured $(\underline{n}=8)$ group ranged from $23-33$ points. The median score was 28 points. The scores from the frustration questionnaire for the non-back-injured group $(\underline{n}=10)$ ranged from 17-32 points. The median score was 27 points.

Table 4 illustrates a cross-tabulation of level of frustration and group. The chi-square statistic was not found to be significant, $X^{2}(2, \underline{N}=18)=2.880$, $p>.05$.

The scores from the overload questionnaire for the back-injured group $(\underline{n}=8)$ ranged from $17-32$ points. The median score was 20 points. The scores from the overload questionnaire for the non-back-injured group $(\underline{n}=10)$ ranged from 16-34 points. The median score was 20 points.

Table 5 illustrates a cross-tabulation of overload level with group. The chisquare statistic was not found to be significant, $x^{2}(2, \underline{N}=18)=1.935, p>05$.

The study concluded that there was no significant difference between the back-injured and the non-back-injured responses to the frustration and overload questionnaires. 
Table 4

Cross-tabulation of Level of Frustration and Group

\begin{tabular}{lccc}
\hline & \multicolumn{3}{c}{ Level of Frustration } \\
& Low & Average & High \\
& $10-20$ & $21-26$ & $27+$ \\
Group & 0 & & \\
Back-injured & $0 \%$ & $50 \%$ & 4 \\
& 2 & 2 & $60 \%$ \\
Non-back-iniured & $20 \%$ & $20 \%$ & $60 \%$ \\
& & & 6 \\
\hline
\end{tabular}

Note. No significant difference between groups $(\underline{\underline{Q}}=.72)$. 
Table 5

Cross-tabulation of Level of Overload and Group

\begin{tabular}{cccc}
\hline & \multicolumn{3}{c}{ Level of Overload } \\
& Low & Average & High \\
Group & $10-20$ & $21-26$ & $27+$ \\
Back-injured & 5 & 1 & 2 \\
Non-back-injured & $62.5 \%$ & $12.5 \%$ & $25 \%$ \\
& 5 & 5 & 0 \\
& $50 \%$ & $50 \%$ & $0 \%$ \\
\hline
\end{tabular}

Note. No significant difference between groups $(p=.82)$. 


\section{Chapter 5 \\ CONCLUSIONS AND RECOMMENDATIONS \\ Conclusions}

This study further explored a significant finding of Owen's research: Back-injured nursing personnel scored higher on measures of the stress factors of frustration and overload than non-back-injured nursing personnel. The present study was designed utilizing the same questionnaires on frustration and overload.

Four hypotheses were tested, two null and two alternative. The first null hypothesis, that there is no difference in frustration scores between back-injured and non-back-injured nursing personnel, was accepted in the analysis of the frustration questionnaires. The alternative hypothesis \# $1 \mathrm{a}$, that scores from nursing personnel in the back-injured group on the frustration questionnaire will be higher than scores from nursing personnel in the non-back-injured group, was rejected in the analysis of the frustration questionnaires. The second null hypothesis, that there is no difference in overload scores between back-injured and non-back-injured nursing personnel, was accepted in the analysis of the overload questionnaires. Alternative hypothesis \#2a, that scores from nursing personnel in the back-injured group on the overload questionnaire will be higher than scores from nursing personnel in the non-back-injured group, was also rejected in the analysis of the overload questionnaires. The results of this study did not support Owen's findings that the stress factors of frustration and overload were significant as risk factors in back injury.

Relating the demographic findings of this study to the review of the literature, a positive family history of back pain (Sheahan, 1982) and increased age (Owen, 1982) were cited as back injury risk factors. No difference in family history of back pain was found in this study between the back-injured and non-back-injured group. This study 
found the non-back-injured group tended to be older than the back-injured group. The literature showed that as nurses age they are increasingly at risk. A possible explanation for the age difference is that back-injured nurses were unable to work as long as the non-back-injured nurses. Hence, the latter group tended to be older in this particular institution. The chi-square between group and age was not found to be significant at the alpha level of .05. However, if the more generous alpha level of .1 had been used, the chi-square statistic would have been significant. As this is confirmatory research, the more stringent alpha level was used and results remain inconclusive.

The number of years worked as nursing personnel revealed that the non-back-injured group had worked longer than the back-injured group. However, the chi-square statistic between group and years worked as nursing personnel was not found to be significant.

Another interesting finding is that the weights of the back-injured group demonstrated a greater deviation from normal when compared to a table of average weight for height and age. This, in conjunction with the significant chi-square statistic between group and amount of exercise, relates to Sheahan's (1982) research that identified lethargy, poor diet, and lack of exercise as risk factors for back injury.

Stubbs (1981) refers to lack of basic lifting skills and failure to utilize the patient's ability to help as possible causes of back injuries. The rounded back method of lifting has long been considered incorrect. Hebert and Miller (1987) propose that the pelvic tilt method of lifting also compromises the back. This is congruent with the researcher's clinical experience as a staff nurse. It has been obser/ed that many nurses fail to practice correct body mechanics. This is especially apparent when going from a rehabilitation unit, where specialized staff nurses often liff correctly, to a general medical-surgical unit where poor habits are abundant and a correct lift is a rare sight. 
A key methodological factor in this study was that the researcher used mailed questionnaires. Response rates to mailed questionnaires vary greatly. "Low response rates can occur, especially with less educated and older addressees inviting a nonrepresentative return" (Isaac \& Michael, 1984, p. 130). It is conceivable that by using mailed questionnaires, only a subset of the population (those who tend to retum mailed questionnaires) was obtained. It is possible that persons in this subset carry a particular bias in their responses to frustration and overload.

The study consisted of a convenience sample of 18 nursing personnel. A small convenience sample biases the findings and limits the generalizability of the outcomes, thereby affecting external validity. It is probable that the results of this study are inconclusive because of the small sample size. It is also conceivable that there is a type Il error, and that the study failed to reject the null hypotheses when they were actually faise.

The use of false dichotomies, in the design of the General Information Sheet by the researcher, limited the specificity of the data analysis. For example, several questions asked the subject to check a range of years. If instead a specific answer in years had been asked, the resulting data would have been more meaningful.

Finally, in analyzing sources of internal validity, the study may have elicited some demand characteristics and may contain a halo effect as well. The researcher is well known to the nursing personnel, having been employed in the study setting in various positions including nurse educator for the past 8 years. Given this, demand characteristics may have been elicited if some of the subjects guessed the goal of the research. This raises the question of the efficacy of doing research in a population where one is personally known. The halo effect, a general effect reflecting the good or poor feelings the subjects may have had about the researcher, may also be present. Both of these effects are threats to internal validity. 


\section{Recommendations}

Clinical implications specific to this study regarding the stress factors of frustration and overload remain inconclusive. The literature strongly suggests a connection between stress and somatic complaints (Frymoyer, Pope, Costanza, Rosen, Goggin, \& Wilder, 1980; Sates, 1988; Girdano \& Everly, 1979; Lazarus \& Folkman, 1984; Owen \& Damron 1984; Pearlin \& Schooler, 1978). However, evidence in support of this concept of psychological stress and its relationship to illness or injury remains ambiguous.

Based on this researcher's experience and current review of the literature, the key to decreasing work-related back injuries lies primarily in prevention through education in safe liffing procedures, correct body mechanics, and prophylactic back care. Primary prevention of back injury involves preventing the initial injury.

Venning (1988a) outlines interventions to prevent back injury based on the health model of host versus stressor. Six means of increasing host resistance and three methods of decreasing the stress factor strength are proposed. Increasing strength, matching strength to task, performing risk factor intervention, training employees in safe liffing procedures and body mechanics, and instructing in back care, all increase host resistance. Methods of decreasing stressor strength include refusing to provide care for heavy clients, increasing the number of personnel to share lifting tasks, and using mechanical lifting aids (1988a, p. 329).

Examining the role of education in back injury prevention among nursing personnel, Venning (1988a), concludes that "an ergonomic approach that considers the intrinsic stress of job tasks is most likely to effect the greatest reduction in back injuries" (p. 332). Thus, while education has maintained a supportive role in training nursing personnel in ergonomically sound lifting procedures, its importance also lies in providing instruction on back care and body mechanics. Instruction in back care 
would include, for example, points on sleeping and sitting positions to maximize recovery from physically stressful periods. McKenzie discusses prophylactic back care in his book Treat Your Own Back (1985). Examples include how to get up from the sitting position by moving to the front of the seat and standing up using the legs (versus bending forward and rounding the back), and utilizing a lumbar roll to maintain correct sitting posture (1985, p. 61). In a sense, the semantics of the English language reflect society's inadequate back care habits in the phrase "back-breaking work." Were proper back care and correct body mechanics optimal, this phrase would be "leg-breaking work."

In examining the instructional design features for back-injury prevention program planning for hospitals, Venning (1988b) identifies back care and body mechanics instruction as critical design features. Back care focuses upon "minimizing postural stress on the spinal unit during periods of low stress through lying and sitting postures" (Nenning, 1988b, p. 337). This gives intervertebral disks and related spinal structures a chance to recover. Clear step-by-step guidelines to instruct nursing personnel in how to move clients with minimal stress are needed.

The following recommendations are made based on the above conclusions and limitations.

1. Additional research is needed on the stress factors of frustration and overload with a larger, randomized sample size.

2. Further research to examine the role of stress in back injury should be carried out.

3. More research is needed to define the role of prophylactic back care (correct sitting, standing, and sleeping positions to reduce strain) in the prevention of back injury. 
REFERENCES 


\section{References}

Andersson, G. B. J. (1981). Symposium: Low-back pain in industry. Spine, $6(1), 52-$ 59.

Arad, D., \& Ryan, M. D. (1986). The incidence and prevalence in nurses of low back pain: A definitive survey exposes the hazards. The Australian Nurses Joumal, $16(1), 44-48$.

Bigos, S. J., Spengler, D. M., Martin, N. A., Zeh, J., Fisher, L., Nachemson, A., \& Wang, $M$. H. Back injuries in industry: A retrospective study: II. Injury factors. Spine, 11(3), 246-251.

Cust, G., Pearson, J. C. G., \& Mair, A. (1972). The prevalence of low back pain in nurses. International Nursing Review, 19(1), 169-179.

Dehlin, O., Berg, S., Andersson, G. B. J., \& Grimby, G. (1981). Effect of physical training and ergonomic counselling on the psychological perception of work and on the subjective assessment of low-back insufficiency. Scandanivan Journal of Rehabilitation Medicine, 13, 1-9.

Frymoyer, J. W., Pope, M. H., Costanza, M. C., Rosen, J. C., Goggin, J. E., \& Wilder, D. G. (1980). Epidemiologic studies of low-back pain. Spine, $5(5), 419-423$.

Gates, S. J. (1988). Muscle weakness is leading cause for nurses' lower back injuries. Occupational Health \& Safety, $\underline{57}(4), 57-63$.

Girdano, D. A., \& Dusek, D. E. (1988). Changing health behavior. Scottsdale, AZ: Gorsuch Scarisbrick.

Girdano, D. A., \& Everly, G. S. (1979). Controlling stress and tension: A holistic approach. New Jersey: Prentice-Hall.

Global population over 60 increasing rapidly; UN role in solving their problems stressed. (1988, March). U. N. Chronicle. 25(1), p. 84. 
Greenwood, J. G. (1986). Back injuries can be reduced with worker training, reinforcement. Occupational Health \& Safety, $\underline{55}(5), 26-29$.

Hebert, L., \& Miller, G. (1987). Newer heavy load lifting methods help firms reduce back injuries. Occupational Health \& Safety, 56(2), 57-60.

Isaac, S., \& Michael, W. B. (1984). Handbook in research and evaluation. San Diego, CA: Edits.

Jensen, R. (1987). Disabling back injuries among nursing personnel: Research needs and justification. Research in Nursing and Health, 10, 29-38.

Johnson, J. E. (1989). Coping with stressful experiences. Advances in Nursing Science, $11(2), 48-51$.

Lazarus, R. S. (1966). Psychological stress and the coping process. New York: Mcgraw-Hill.

Lazarus, R. S., Kanner, A. D., \& Folkman, S. (1980). Emotions: A cognitivephenomenological analysis. In A. Monet, \& R. S. Lazarus (Eds.), Stress and coping: An anthology (pp. 192-200). New York: Columbia University Press.

Lazarus, R. S., \& Folkman, S. (1984). Stress, Appraisal, and Coping. New York: Springer Publishing Company.

Leedy, P. (1985). Practical research: Planning and design. New York: Macmillan Publishing Co.

Lortie, M. (1987). Structural analysis of occupational accidents affecting orderlies in a geriatric hospital. Journal of Occupational Medicine, 29(5), 437-444.

Magora, A., \& Taustein, I. (1969). An investigation of the problem of sick-leave in the patient suffering from low back pain. Industrial Medicine, 38 (1 1), 80-90. 
Mandel, J. H., \& Lohman W. (1987). Low back pain in nurses: The relative importance of medical history, work factors, exercise, and demographics. Research in Nursing and Health, 10, 165-170.

McKenzie, R. (1985). Treat your own back. New Zealand: Wright and Carman Limited.

Miller. J. D., \& Myers M. L. (1983). Occupational safety and health: Progress toward 1990 objectives for the nation. Public Health Reports, 98, 324-336.

National Institute for Occupational Safety and Health. (1985). Program of the national institute for occupational safety and health: FY 1985 Program Plan: Department of Health and Human Services (NIOSH Publication No. 85-108). Atlanta, Georgia: Center for Disease Control.

Owen, B. D. (1982). The relationship of selected personal characteristics to back injury in hospital nursing personnel. Unpublished doctoral dissertation, University of Wisconsin-Madison.

Owen, B. D. (1986). Personal characteristics important to back injury. Rehabilitation Nursing, $11(4), 12-16$.

Owen, B. D., \& Damron, C. F. (1984). Personal characteristics and back injury among hospital nursing personnel. Research in Nursing and Health, Z, 305-313. Parnianpour, M., Beijani, F. J., \& Pavlidis, L. (1987). Worker training: the fallacy of a single, correct lifting technique. Ergonomics, 30(2), 331 -334.

Pearlin, L. I., \& Schooler, C. (1978). The structure of coping. Journal of Health and Social Behavior, 19(3), 2-21.

Pennsylvania State University. (1972). Minitab [Computer Program]. Pennsylvania: Minitab. 
Polit, D. F., \& Hungler, B. P. (1987). Nursing research: Principles and methods (3rd ed.). East Washington Square, Philadelphia: J. B. Lippincott.

Ryan, B. F., Jioner, B. L., \& Ryan, T. A. (1985). Minitab handbook (2nd ed.). Boston: PWS-Kent Publishing Company.

Runyon, R., \& Haber, A. (1984). Fundamentals of behavioral statistics, (5th ed.). Menlo Park, CA: Addison-Wesley.

Seyle, H. (1982). History and present status of the stress concept. In L. Goldberger, and S. Breznits (Eds.). Handbook of stress: Theoretical and clinical aspects (pp. 7-17). New York: Free Press, Macmillan.

Sheahan, S. (1982). Assessment of low back pain. Nurse Practitioner, Z(5), 15-23.

Snook, S. H., (1988). The costs of low back pain in industry. Occupational Medicine: State of the Art Reviews, $3(1), 1-5$.

Snook, S. H., Campanelli, R. A., \& Hart, J. W. (1978). A study of three preventive approches to low back pain. Journal of Occupational Medicine. 20(7), 478 . 481.

Spatz, C., \& Johnson, J. O. (1984). Basic Statistics: Tales of Distributions (3rd ed.). Monterey, CA: Brookes/Cole.

Spengler, D. M., Bigos, S. J., Martin, N. A., Zeh, J., Fisher, L., \& Nachemson, A. (1986). Back injuries in industry: A retrospective study: I. Overview and cost analysis. Spine, 11(3), 241-245.

Stubbs, D. A., Buckle, P. W., Hudson, M. P., Rivers, P. M., \& Worringhamm, C. J. (1983). Back pain in the nursing profession: Epidemiology and pilot methodology. Ergonomics, 26(8), 755-765.

Stubbs, D. A., Rivers, P. M., Hudson, M. P., \& Worringham, C. J. (1981, May 14). Back pain research. Nursing Times, $\underline{77}, 857-8$. 
The world almanac and book of facts, (1989). New York: Scripps Howard Company, St. Martins Press.

Tomer, G. M., Olsen, C. N, \& Lepore, B. (1984). Back injury prevention training makes dollars and sense. National Safety News, 36-39.

Venning, P. J. (1988a). Back injury prevention among nursing personnel. American Association of Occupational Health Nurses Journal, 36(8), 327-333.

Venning, P. J. (1988b). Back injury prevention: Instructional design features for program planning. American Association of Occupational Health Nurses Joumal, 36(8), 336-339.

Webster's ninth new collegiate dictionary. (1988). Springfield, MA: Merriam-Webster.

White, A. A., \& Gordon, S. L. (1982). Synopsis: Workshop on idiopathic low-back pain. Spine, Z(2), 141-149. 


\section{APPENDIX A}

\section{Research Instruments}


The Research Instruments

The scoring of Questionnaire A (Frustration):

Questions 1 and 10: $a=1, b=2, c=3, d=4$;

Questions 2-9: $a=4, b=3, c=2, d=1$.

The scoring of Questionnaire B (Overload):

Questions 1-10: $a=4, b=3, c=2, d=1$. 


\section{PLEASE NOTE:}

Copyrighted materials in this document have not been filmed at the request of the author. They are available for consultation, however. in the author's university library.

These consist of pages:

$50-51$

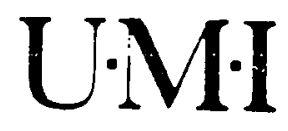


GENERAL INFORMATION SHEET

Please circle, check, or write in the most appropriate answer.

1. Your nursing service title:

$$
\begin{array}{ll}
\text { NA } & \text { LVN } \\
\text { RN } & \text { OTHER }
\end{array}
$$

2. How many years have you worked as a nurse?

$$
\begin{array}{ll}
\text { Less than one year } & 11-20 \text { years } \\
1-3 \text { years } & 21-35 \text { years } \\
\text { 4-7 years } & \text { Greater than } 35 \text { years } \\
8-10 \text { years } &
\end{array}
$$

3. Does anyone in your family have a history of back pain? YES NO

4. Have you had a back injury in the past year? YES NO

If you answered YES to \#4, please answer (a), (b) and (c):

(a) Was it documented at work?

YES NO

(b) Have you changed anything in your life since the injury? _ (If yes, briefly describe changes.)

(c) Age of onset of backpain:

5. Employment status: Full-Time Employee Part-Time Employee

6. Marital status:

$$
\text { Single Married Divorced widowed }
$$


7. Sex: Female Male

8. Educational Preparation: (Check all that apply) Did not finish High-school High-school Graduate NA Certification

L LVN Degree

RN: _ AA Degree _ Diploma Degree _ BSN
Masters in Nursing
AA Degree (Other than as RN)
Bachelors Degree (Other than as RN)
Masters Degree (Other than in Nursing)
Ocher: (write in)

9. Your age:

$\begin{array}{ll}\text { Less than } 20 & 40-49 \\ 20-29 & 50-59 \\ 30-39 & 60-69 \\ & \text { Greater than } 70\end{array}$

10. Height:

11. Weight:

12. Activity level outside of work:

Sedentary (No Exercise)

Light (Exercise 1-2 hours per week)

Moderate (Exercise 3-5 hours per week)

Heavy (Exercise greater than 5 hours per week) 
APPENDIX B

Consent Lefter

and

Cover Letter 
AGREEMENT TO PARTICIPATE IN RESEARCH AT SAN JOSE STATE UNIVERSITY

RESPCNSIELE INVESTIGATOR: Karén GabriElson, C.R.R.N.

TITLE OF PROTOCDL: The Relationship Retween Pack Ir.jury and the Foychosocial Stressors of Frustration and overload.

I fiave been asled to perticifate in a research study that is investigating the relationstip between back injury and the psuchosocial stressors of frustiatien and overloat. The results of this stusty should further our understanding of bacl: injuries and their possible prevention.

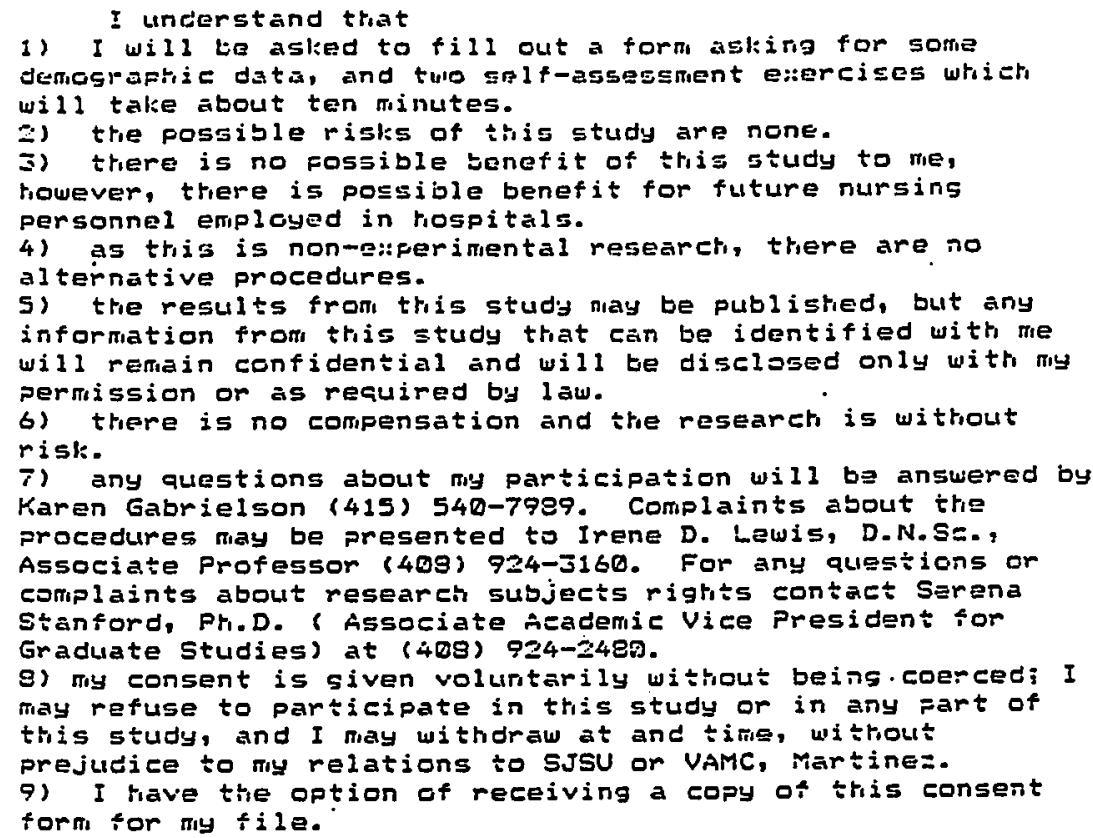

I HAVE MADE A DECISION WHETHER OR NOT TO PARTICIPATE. MY SIGNATURE INDICATES THAT I HAVE READ THE INFORMATION PROVIDED AZOVE AND THAT I HAVE DECIDED TO PARTICIPATE.

$10 / 12 / 28$ DATE

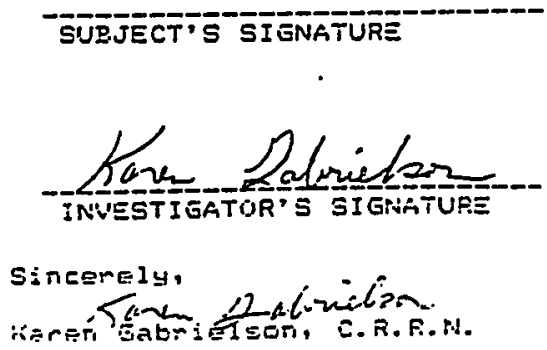


Dear Kuraing Personnel.

I am currently a graduate student at San Jose State University and $a m$ an employee of VAMC Martinez Nursing Service. For my liacters theris I am doing a study about etreas and buck injury. I rould islie to invite you to participate in this etudy. It rould take obout 10 minutea of your time and involve completing tro belf-Bssessment queetionnalrea and a general information sheet.

The purpose of the study 18 to find out 1 there sre differences in certain personal charactertetics betreen back injured end non-beck-Injured nuraing personnel. Findings of this study will help us os nurses in urderstanding and poseibly preventing back injuries.

kny information you provide vill te confidentiel and *11l be identiflable only by a code number. Your name w111 not be on any questionnaire. Access to this data 1s $11 \mathrm{mited}$ to the investigator (myeelf). Results of the study vill be in the form of group data thereby making 1 it imposeible to Identify any individuel. The questionneires which you return vil1 be kept in a locked file cabinet until the Information is tabulated, after rhich the questionneires w11 be burned.

A coneent form is included which is for your 1.zformation, protection and resords. You do not need to return the consent form.

Consent to perticipate is acisnoxledged by your completing and returning the questionalatres. A stamped, adoiressed envelope is enclosed to return the questionnaires and Information cheet. Feeults of this study will be avaliable through the hospltal kuraing Service.

If you vould like to discuss this etudy further, you can contact me at $415-540-7989$.

I thenk you for your time end consideretion of this request.

Sincerely,

Karen Gabrielson, BN-C, BSN 
APPENDIX C

Permission Letter 


\title{
$\begin{array}{llllllllllll}\mathbf{P} & \mathbf{R} & \mathbf{E} & \mathbf{N} & \mathbf{T} & \mathbf{I} & \mathbf{C} & \mathbf{E} & \mathbf{H} & \mathbf{A} & \mathbf{L} & \mathbf{L}\end{array}$
}

\section{COLLEGE BOOK DIVISION}

April 28, 1988

\author{
Karen Gabrielson, CRRN \\ 1940 Delaware St. \\ Berkeley, CA 94709 \\ Dear Ms. Gabrielson:
}

We are very glad to give you permission to quote from our book(s), CONTROLLING STRESS \& TENSION by Girdano and Everly.

in accordance with the conditions outlined in your letter of $3 / 7 / 88 \& 4 / 20 / 88$ For your study only.

Please give credit to the author(s), the efiele(s), and the publisher with copyright year date(s). Our usual credit line appears below: Daniel A. Girdano/George S. Everly, CONTROLLING STRESS \& TENSION : A Holistic Approach, (c) I979,pp.62,67-8. Reprinted by permission of Prentice Hail, Inc., Englewood Cliffs, New Jersey.

Sincerely,

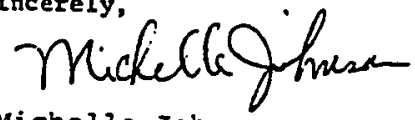

Michelle Johnson

Permissions Editor

$9.1 / 20880$

Simon \& Schuster Higher Education Group

Prentice Hall Building. Englewood Cliffs. NJ 07632 (201) 592-2000 


\section{APPENDIX D}

Human Subjects Approval

59. 


\section{SAN JOSE STATE UNIVERSITY \\ GRADUATE STUDIES AND RESEARCH \\ HUMAN SUBJECTS INSTITUTIONAL REVIEW BOARD IU TOUIOATIO:!

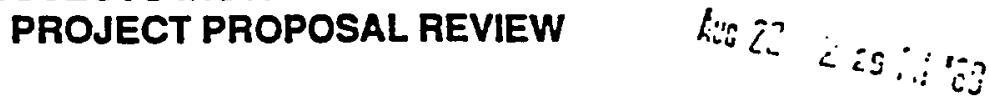

I. the undersigned member of the San Jose State University Human Subjects

Institutional Review Board, have reviewed the following proposal submitted to the

Committee on August 1\%,1988_ by:

PRINCIPAL INVESTIGATOR: Karen Gabrielson

PROTOCOL \#: $7346 \quad$ DEPT.: Nursing

PROJECT TITLE: "BACK INJURY AND THE PSYCHOSOCIAL STRESSORS OF

FRUSTRATION AND OVERLOAD AMONG NURSES III AN ACUTE HOSPITAL."

I recommend the following action (iridicate one):

1. Approved for clearance as involving minimal risk to Human Subjects.

2. Approved for clearance with risk to Human Subjects.

3. Approved for clearance when the following conditions are met:

$\cdot$

4. Not Approved (return to principal investigator for following reasons):

5. Expedited Review (specify condition[s] that merit expedited review):

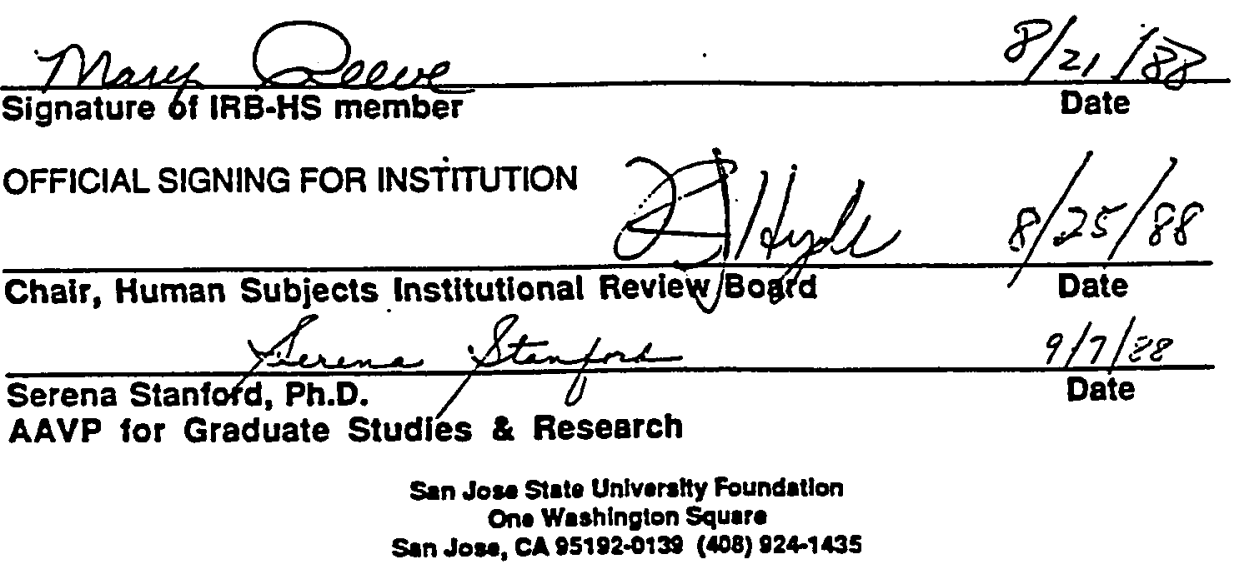

